\title{
PURIFICATION OF HORDEIN POLYPEPTIDES BY COLUMN CHROMATOGRAPHY USING VOLATILE SOLVENTS
}

\author{
by \\ JÜRGEN M. SCHMITT \\ Department of Physiology, Carlsberg Laboratory \\ Gamle Carlsberg Vej 10, DK-2500 Copenhagen Valby
}

Keywords: Barley, prolamin, gel filtration, ion exchange chromatography, amino acid composition

\begin{abstract}
Hordein polypeptides $\mathrm{C} 2$ and $\mathrm{B} 1$ have been purified using gel filtration and ion exchange chromatography in volatile solvents. They are different in amino acid composition, the Bl-hordein containing lower amounts of glutamine/glutamic acid and proline. By digestion with carboxypeptidase $\mathrm{Y}$ the $\mathrm{C}$-terminal sequence Gly-Val$\mathrm{COOH}$ was deduced for the $\mathrm{BI}$ polypeptide whereas no clear sequence could be established from the amino acids $\mathrm{Ser}, \mathrm{Val}$, Ile and Met which were released from the C2-hordein. This indicates possible heterogeneity of the C2 component.
\end{abstract}

\section{INTRODUCTION}

Hordein, the alcohol-soluble prolamin of the barley endosperm, is characterized by a high content of glutamine and proline. This group of reserve proteins can be separated into a number of discrete polypeptide bands by electrophoresis in the presence of sodium dodecyl sulfate (SDS). The polypeptides of the cultivar Bomi range in molecular weight from about 27 to $67 \mathrm{kD}$ and chymotryptic peptide mapping reveals structural homology as well as distinct differences among the separated bands, designated as hordein $\mathrm{B} 1$ to B3 and hordein C1 to C5 (4). Some of these polypeptides display heterogeneity, when analyzed in an additional isoelectric focusing dimension (9, 13). Cloning of a double stranded DNA complementary to one messenger RNA molecule revealed the latter to code for a $\mathrm{Bl}$-hordein polypeptide which is partly homologous to the B2-hordein (1). According to these results the various hordein polypeptides are translated from different messenger RNA molecules. For the further analysis of the organization and expression of the hordein genes additional information on the primary structure of the different hordein polypeptides is required. Techniques to separate 
the various hordein polypeptides on a preparative scale have therefore been explored.

Attempts to fractionate hordein by free-flow electrophoresis (16) or gel filtration in the presence of urea (8) have yielded cross-contaminated fractions, with the possible exception of one $\alpha$-hordein (8). This corresponds to a Ahordein with the presently used nomenclature (see Mifuin and Shewry, 10). The A-fraction, however, is no longer considered to be hordein proper as it is not deposited in endosperm protein bodies (5). Purifying hordein polypeptides by one- or twodimensional polyacrylamide gels gives very pure fractions in low yield $(4,9)$.

I have developed fractionation methods capable of providing large quantities of pure polypeptides, suitable for further analysis. The rationale of this approach was to purify hordein polypeptides in columns with different stationary phases using alcohols and volatile salts as mobile phases in order to simplify retrieval of the isolated fractions.

\section{MATERIALS AND METHODS}

\subsection{Isolation of hordein from barley meal}

Barley seeds (Hordeum vulgare L.) cv. Bomi were ground in an Udy Cyclone mill. The meal $(100 \mathrm{~g})$ was stirred at room temperature for 30 min in 1 litre of a solution containing $1 \%$ mercaptoethanol, $1 \mathrm{~mm}$-phenylmethylsulfonylfluoride, $1 \mathrm{~mm}$-EDTA and $0.1 \%(\mathrm{w} / \mathrm{v})$ polyvinylpyrrolidone 10,000 . The suspension was then centrifuged for $10 \mathrm{~min}$ at $13,000 \mathrm{rpm}$ in a Sorvall GSA rotor. The pellet was stirred vigorously for 3 hours at $60^{\circ} \mathrm{C}$ under protective gas containing a chloro-fluoro carbon compound (Protectan, Tetenal-Werke, Hamburg, Germany) in 1 litre of $55 \%$ isopropanol, $2 \%$ mercaptoethanol. The suspension was centrifuged at room temperature under the above conditions. The supernatant was clarified by filtration and dialyzed extensively against $100 \mathrm{~mm}$-mercaptoethanol in the coldroom to precipitate the hordein polypeptides. The dialysis residue was centrifuged at $4^{\circ} \mathrm{C}$ for $30 \mathrm{~min}$ at $13,000 \mathrm{rpm}$ in the Sorvall GSA rotor. The sediment was stirred in 5 litres $55 \%$ isopropanol, $100 \mathrm{~mm}$-mercaptoethanol as described above until it had completely dissolved. The solution was stored at $4^{\circ} \mathrm{C}$ or at $-18^{\circ} \mathrm{C}$ under Protectan gas. The hordein precipitated under these conditions and was redissolved by heating to $60^{\circ} \mathrm{C}$ before use. All columns were run at room temperature.

\subsection{Gel filtration on Sephadex LH60}

Total hordein (up to $25 \mathrm{ml}$ ) was chromatographed on a column $(2.6 \times 30 \mathrm{~cm})$ of Sephadex LH60 (Pharmacia), equilibrated with $55 \%$ isopropanol, $0.1 \%$ mercaptoethanol. The proteins were eluted under $1 \mathrm{~m}$ of hydrostatic pressure. The effluent from the column was monitored at $280 \mathrm{~nm}$.

\subsection{Gel filtration on Sephacryl S300}

$50 \mathrm{ml}$ of hordein solution was applied to a column $(5 \mathrm{~cm} \times 90 \mathrm{~cm})$ of Sephacryl S300 (Pharmacia) and eluted with $55 \%$ isopropanol, $0.1 \%$ mercaptoethanol at a flow rate of 40 $\mathrm{ml} \cdot$ hour $^{-1}$. Afterwards the column was washed with $15 \mathrm{ml}$ of $1 \%$ acetic acid in column medium to remove bound material.

\subsection{Ion exchange chromatography}

Hordein was dialyzed against $60 \%$ isopropanol, 20 mm-ammonium bicarbonate, $0.1 \%$ mercaptoethanol, $\mathrm{pH} 8.8$, and loaded on a 2.6 $\mathrm{cm} \times 10 \mathrm{~cm}$ column of DEAE-Sepharose CL-6B (Pharmacia), equilibrated with the same buffer. The column was washed at $60 \mathrm{~cm}$ hydrostatic pressure with starting buffer until the absorption at $280 \mathrm{~nm}$ wavelength had returned to the initial baseline level. The bound proteins were then eluted with a $\mathrm{pH}$-gradient produced with increasing concentrations of ammonium acetate in $60 \%$ isopropanol, $0.1 \%$ mercaptoethanol until a concentration of $10 \mathrm{~mm}$-ammonium acetate, $\mathrm{pH} 7.2$, was reached. The $\mathrm{pH}$ of the starting and limiting buffer was measured with a glass electrode prior to the addition of mercaptoethanol.

\subsection{Polyacrylamide gel electrophoresis in so- dium dodecyl sulfate}

Slab gels of $1 \mathrm{~mm}$ thickness containing $12.5 \%$ acrylamide or $15 \%$ acrylamide with $2 \mathrm{M}$-urea were run in Laemmli's buffer system (6). The ratio of acrylamide to bisacrylamide was 37.5:1. 
The samples were dried in vacuo in the presence of 250-500 $\mu \mathrm{g}$ SDS and dissolved in Laemmli's sample buffer, heated to $100^{\circ} \mathrm{C}$ for 1-2 min and run at 20-25 mA constant current over night. Gels were fixed in $10 \%$ trichloroacetic acid and stained in a solution containing $0.1 \%-0.2 \%$ Coomassie blue R $250,50 \%$ Methanol and 10\% acetic acid. Gels were partially destained in the same solution without Coomassie blue and then in $10 \%$ trichloroacetic acid (J. INGVERSEN, personal communication). This greatly enhanced the staining intensity of the C-hordein.

\subsection{Amino acid analysis}

Samples were hydrolyzed in evacuated ampoules with $6 \mathrm{~N} \mathrm{HCl}$ containing $0.1 \%$ phenol for 24 hours at $110^{\circ} \mathrm{C}$, dried and analyzed on a Durrum D500 analyzer. Cysteine and methionine were determined using performic acid oxidised samples (3).

\subsection{Carboxypeptidase $Y$ digestion}

Carboxypeptidase $\mathrm{Y}$ was kindly supplied by Dr. IB Svendsen. Digestions were made in 0.1 $\mathrm{M}$-N-ethylmorpholine acetate buffer, $\mathrm{pH} 7.0$, containing $0.5 \%$ SDS (7) and norleucine as an internal standard. Incubation temperature was $30^{\circ} \mathrm{C}$. Enzyme-protein ratios are given in the legend to Figure 5 . The reaction was stopped by acidification with $\mathrm{HCl}$.

The samples were dried in vacuo, resuspended in citrate buffer, centrifuged and the supernatants were run on the amino acid analyzer.

\section{RESULTS}

\subsection{Gel filtration on Sephadex LH60}

To purify hordein from low molecular weight contaminants, gel filtration in Sephadex LH60 was employed using $55 \%$ isopropanol, $0.1 \%$ mercaptoethanol as eluent. An elution profile of a typical separation is shown in Figure 1. The peak representing the excluded volume is skewed. This is caused by a slight retardation of the B-hordein polypeptides (see Figure 2). Since the manufacturer states a fractionation range of up to about $20 \mathrm{kD}$, this retardation of the more than $27 \mathrm{kD} \mathrm{B}$-hordein is thought to be due to adsorption effects.

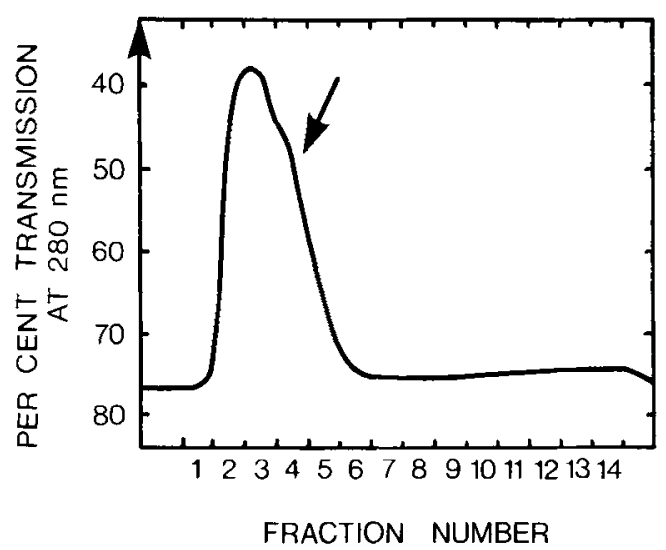

Figure 1. Elution profile of hordein chromatographed on Sephadex LH 60. Fractions of $12 \mathrm{ml}$ were collected.

The arrow points to a shoulder in the peak which elutes with the excluded volume.

\subsection{Gel filtration on Sephacryl S300}

For fractionation according to molecular size, Sephacryl S300 was chosen as stationary phase, again with $55 \%$ isopropanol, $0.1 \%$ mercaptoethanol as eluant. As can be seen in Figure 2, the individual hordein polypeptides did not elute in the order of decreasing molecular weight, as determined by electrophoresis in the presence of sodium dodecyl sulfate. The Bl polypeptide was adsorbed on the column. The adsorbed material could be released from the column by washing with a small volume of $1 \%$ acetic acid in the eluant, as shown in Figure 3.

Two polypeptide size classes could be obtained from this column in purified form: An early eluting C2-hordein, which possibly consists of two polypeptide chains (see fractions $16-20$ in Figure 2) as well as B1-hordein from the acetic acid wash (fractions 18-21 in Figure 3). These two fractions were used for further analysis.

\subsection{Ion exchange chromatography}

The approach employing high concentrations of isopropanol as chromatographic solvent appears also useful for separation of hordein polypeptides by ion exchange chromatography. With DEAE Sepharose CL-6B as adsorbent, volatile salts (ammonium bicarbonate and ammonium acetate) were chosen as ionic compo- 


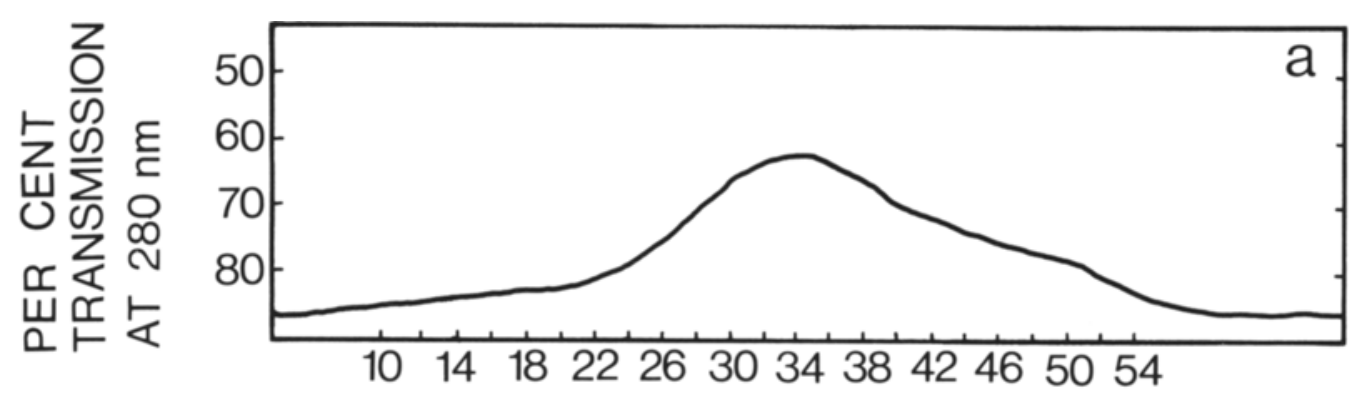

FRACTION NUMBER

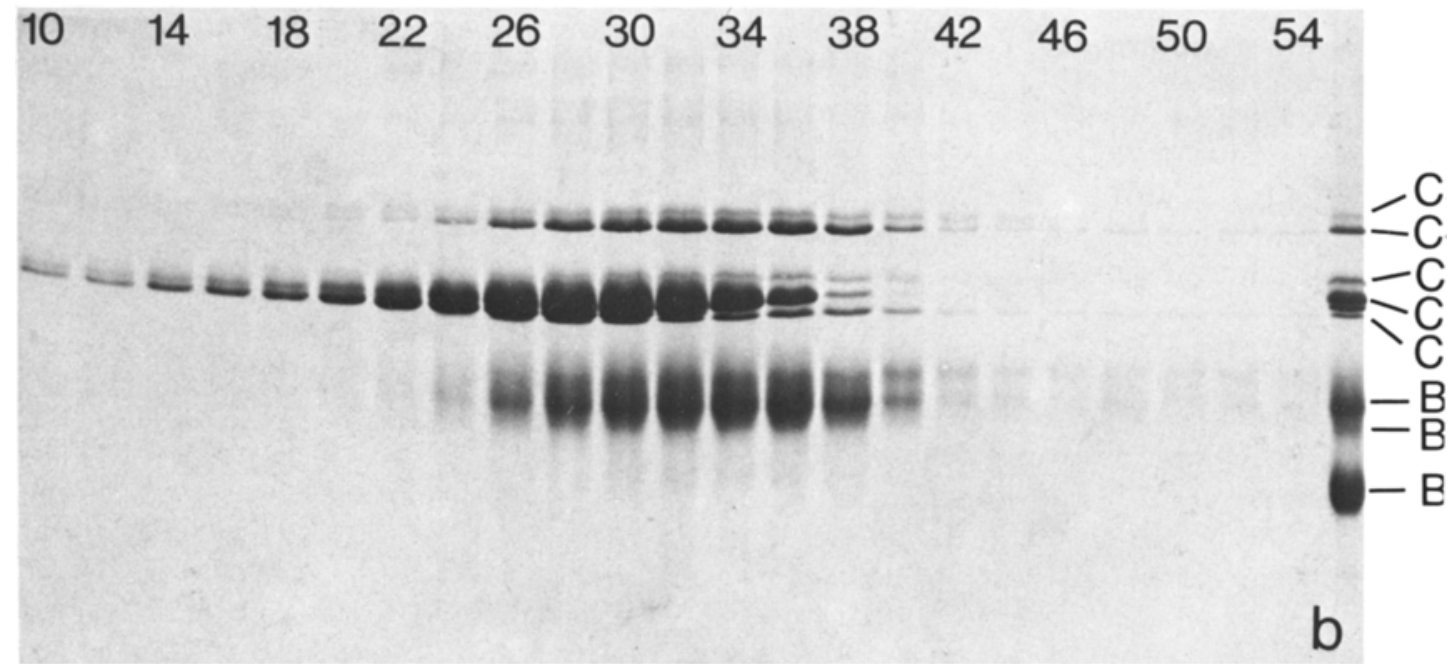

Figure 2. (a) Elution profile of hordein chromatographed on Sephacryl S300. Fractions of $13 \mathrm{ml}$ were collected. (b) Gel electrophoretic analysis of the fractions from the column (cf. 3.2). The right lane contains total hordein (cf. 2.1) for comparison. The designation of the polypeptides is according to Holder and INGvERSEN (4). Note the double band in lane 20 .

nents of the eluant. A separation is shown in Figure 4. The B1 polypeptide is not bound to the column and elutes in three peaks of high purity. This elution behaviour is consistent with the alkaline isoelectric point as determined by isoelectric focusing and the three peaks possibly represent the isoelectric variants described by Miflin \& Shewry (10). Some of the C-hordein polypeptides are eluted with a $\mathrm{pH}$-gradient using $10 \mathrm{~mm}$-ammonium acetate, $\mathrm{pH} 7.2$ as a limiting buffer.

\subsection{Amino acid analysis}

Amino acid analysis of the purified B1 and C2 polypeptides give quite different compositions for these two proteins (Table I). The C2-hordein contains higher amounts of glutamic acid/ glutamine and proline, but lower amounts of threonine, valine, methionine, isoleucine, leucine and lysine which are essential for mammalian nutrition. Phenylalanine is the only essential amino acid which is lower in the $\mathrm{Bl}$ polypeptide (tryptophane has not been determined). Particu- 
larly striking is the low lysine content of the $\mathrm{C}$ hordein, amounting to about 1 lysine residue per chain.

\subsection{Carboxypeptidase $Y$ digestion}

Carboxypeptidase $\mathrm{Y}$ was used for $\mathrm{C}$-terminal analysis in the presence of sodium dodecyl sulfate to keep the hordein polypeptides in solution. The time course of the digestion for the two purified hordein polypeptides is shown in Figure 5. A clear release pattern for the B1hordein suggests the sequence -Gly-Val-COOH. The C2-hordein fraction displays more complicated kinetics, indicating that the carboxyterminal sequences of two different polypeptide chains may be present in this hordein preparation. This can also be seen in the electrophoretic patterns of Figure 2. Possible sequences could be -Val-Ser$\mathrm{COOH}$ and $-\mathrm{Ile}-\mathrm{Met}-\mathrm{COOH}$.

\section{DISCUSSION}

Three chromatographic fractionation methods for hordein polypeptides all based on isopropa-

\section{Table I}

Amino acid composition of hordein polypeptides C2 and $B 1$.

\begin{tabular}{lcc}
\hline & \multicolumn{2}{c}{ Mole \% } \\
Amino acid & $\begin{array}{c}\text { Residues / 100 Residues } \\
\text { Isolated hordein polypeptides }\end{array}$ \\
\hline Cysteine & B1 & C2 \\
Aspartic acid & 2.8 & 0.9 \\
Threonine & 1.5 & 1.2 \\
Serine & 1.8 & 1.2 \\
Glutamic acid & 2.9 & 2.1 \\
Proline & 34.2 & 41.1 \\
Glycine & 16.8 & 27.4 \\
Alanine & 3.8 & 1.2 \\
Valine & 3.0 & 1.0 \\
Methionine & 6.1 & 1.6 \\
Isoleucine & 1.1 & 0.6 \\
Leucine & 4.1 & 3.7 \\
Tyrosine & 8.8 & 5.2 \\
Phenylalanine & 2.5 & 2.5 \\
Histidine & 4.7 & 8.0 \\
Lysine & 1.6 & 0.7 \\
Arginine & 1.0 & 0.2 \\
\hline & 2.8 & 1.7 \\
\hline
\end{tabular}
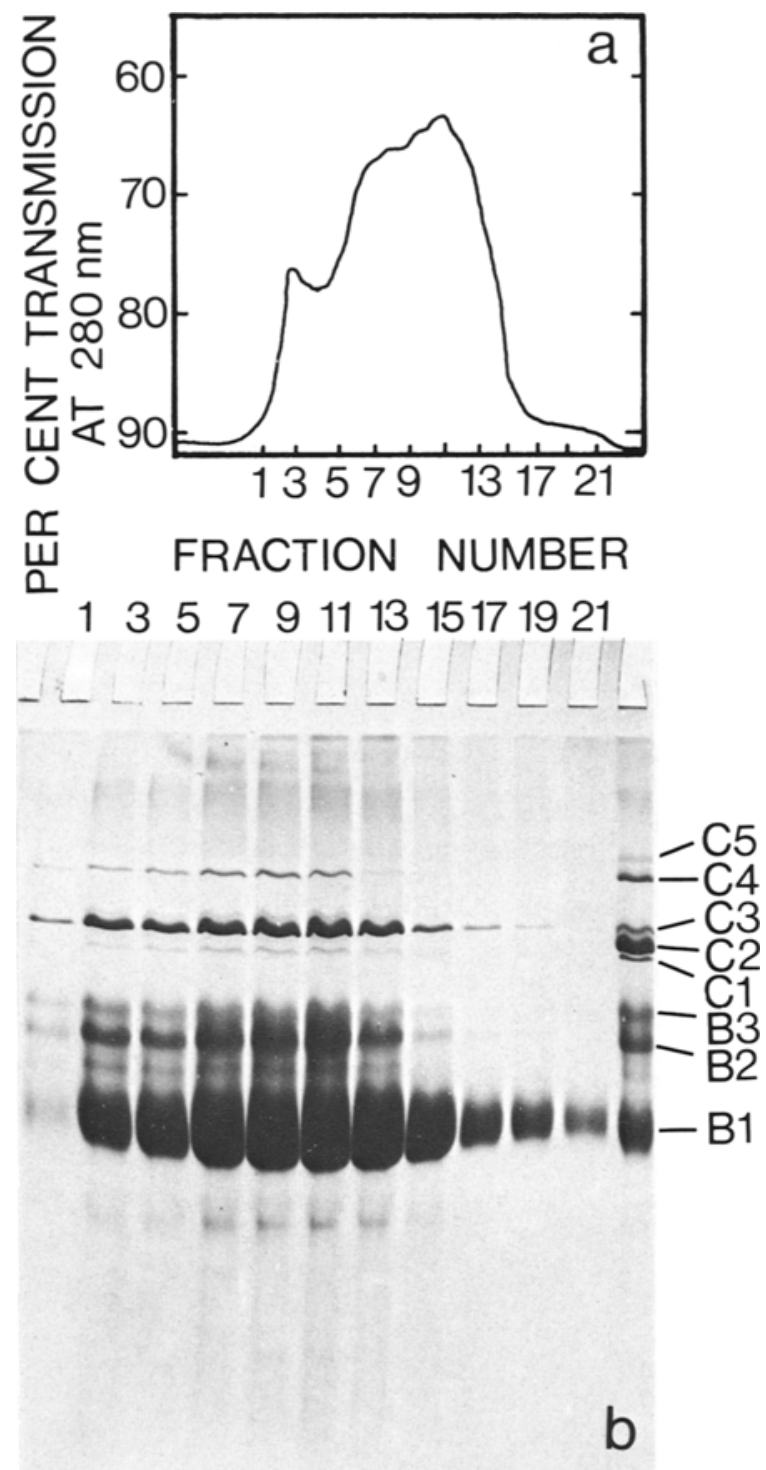

Figure 3. Release of polypeptides adsorbed to Sephacryl S300 with acetic acid (cf. 2.3).

(a) Elution profile. (b) Gel electrophoresis of eluted fractions. The right lane contains total hordein (cf. 2.1) for comparison.

nol-water solutions as eluants have been described. They allow the purification of the $\mathrm{C} 2$ and the B1 polypeptides. In addition, they may be useful in obtaining fractions enriched in other hordein polypeptides, which then may serve as starting 


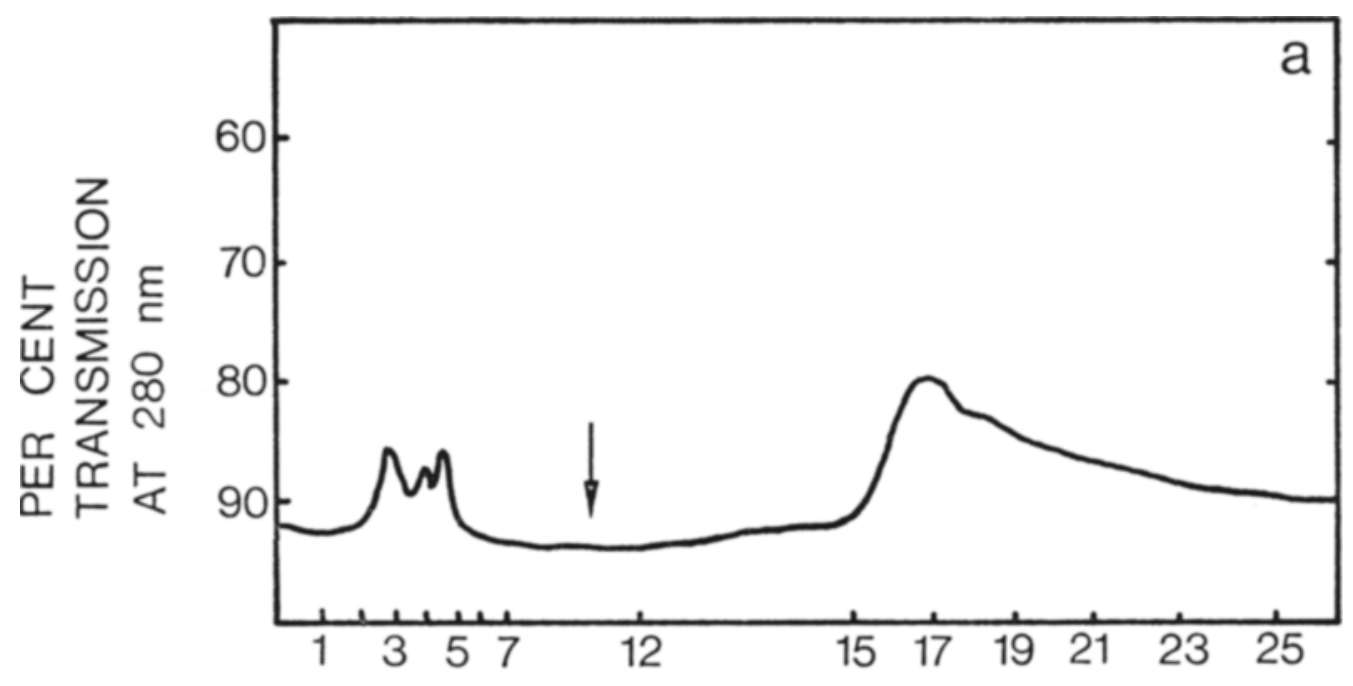

FRACTION NUMBER

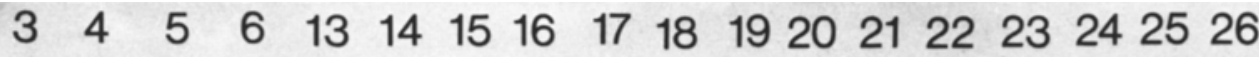

Figure 4. Ion exchange chromatography of hordein on DEAE Sepharose CL-6B.

(a) Elution profile. The arrow designates the start of the gradient (cf. 2.4). (b) Gel electrophoresis of eluted fractions. The right lane contains total hordein (cf. 2.1) for comparison.

material for further purification (see Figures 2, 3 and 4).

It should be mentioned that the Sephacryl S300 separation depended strongly on the conditions described. For instance, inclusion of $1 \%$ acetic acid in the $55 \%$ isopropanol to achieve elution in one step resulted in a greatly reduced resolution. The ion exchange method, on the other hand, provides flexibility for the choice of salt, $\mathrm{pH}$ and gradient shape to enrich for other hordein polypeptides.

Amino acid analysis shows that the isolated 


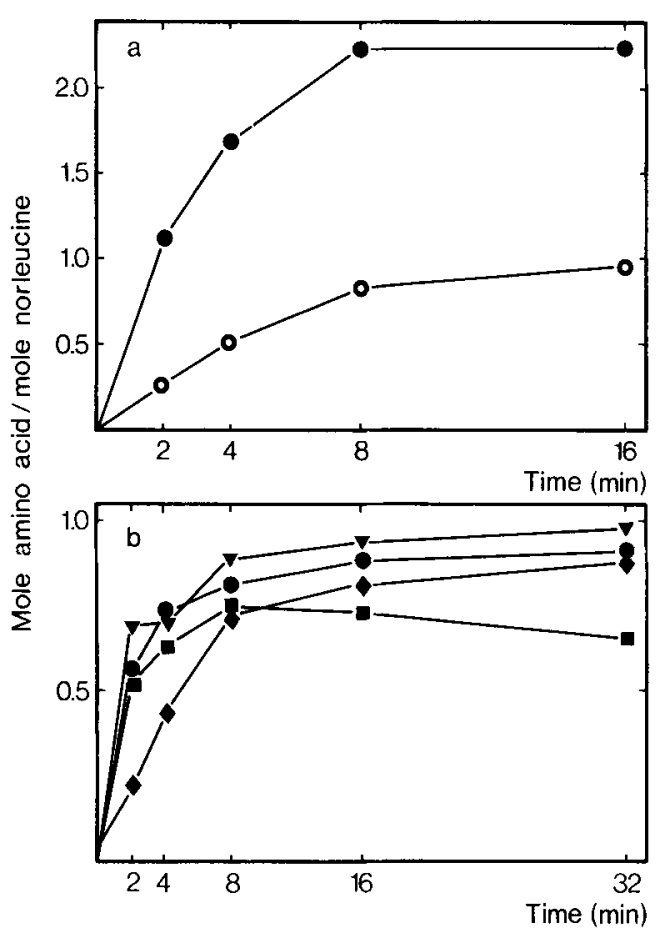

Figure 5. Time course of carboxypeptidase $\mathrm{Y}$ digestion.

(a) Digestion of $2 \mathrm{mg} \mathrm{Bl}$ hordein with $9 \mu \mathrm{g}$ of carboxypeptidase $\mathrm{Y}$ in a total volume of $1.5 \mathrm{ml}$. Val (๑), Gly (O). (b) Digestion of $2.5 \mathrm{mg} \mathrm{C} 2$ hordein with $6 \mu \mathrm{g}$ of carboxypeptidase $Y$ in a total volume of $2.5 \mathrm{ml}$. The identity of the released amino acids was confirmed by dansylation as described by Poutsen (12). Weak spots of glutamic acid and aspartic acid were found after hydrolysis for 4 hours in addition to the residues shown in the figure. $\operatorname{Ser}(\boldsymbol{\nabla}), \operatorname{Val}(\boldsymbol{\bullet})$, Met (ם), Ile ( $)$.

$\mathrm{B} 1$ and $\mathrm{C} 2$ polypeptides are different in composition. The B1-hordein contains about 5 times as much lysine as the $\mathrm{C} 2$-hordein on a mole per cent basis. It is furthermore higher in content for almost all amino acids which are essential for human nutrition (section 3.4). To improve the nutritional value of barley it may therefore be useful to breed for mutants with an increased content of B1-hordein. Carboxypeptidase $\mathrm{Y}$ releases different $\mathrm{C}$-terminal amino acids from the purified polypeptides. The results indicate one sequence -Gly-Val-COOH from the $\mathrm{Bl}$ hordein, but possibly two sequences for the $\mathrm{C} 2$ hordein, involving the amino acids Ser, Met, Val and Ile. The presence of one of the two methionine residues in the $\mathrm{C} 2$-hordein close to the carboxyterminus is interesting, since I have not succeeded in producing fragments from the C2-hordein by treatment with cyanogen bromide (as judged by SDS gel electrophoresis). If this result is not caused by an artifact due to the highly hydrophobic nature of the hordein polypeptides, I would expect the other methionine residue to be located near the $\mathrm{N}$ - or $\mathrm{C}$ terminus, and it becomes understandable that $\mathrm{CNBr}$-cleavage does not alter the apparent molecular weight significantly.

The differences in total amino acid composition of the $\mathrm{B} 1$ - and $\mathrm{C} 2$-hordein polypeptides and in the structure of the carboxy-terminus supports the conclusion reached by the analysis of the messenger RNA for the B1-hordein (1), namely that the different hordein polypeptides have distinct primary structures.

The B-hordein polypeptides and the C-hordein polypeptides are coded for by the hor -2 and hor- 1 regions on chromosome 5 , respectively $(2,11$, 14, 15). Further studies will have to show whether the primary structure differences among the B-hordeins or among the C-hordeins in general are as large as those found here between the $\mathrm{B} 1$-hordein and the $\mathrm{C} 2$-hordein. This will provide a basis for rational improvement of the quality of the hordein proteins by plant breeding.

\section{ACKNOWLEDGEMENTS}

I am grateful to those who helped me during the course of this work: Professor DITER vON WETTSTEIN critically read the manuscript, CARsten Poulsen, Dr. Ib Svendsen and Dr. Karen WeLINDER (Institute of Genetics, University of Copenhagen) helped with discussions and suggestions. BODIL CORNELIUSSEN did the amino acid analyses. ANN-Sofi Steinholtz and Nina RaSMUSSEN provided photographs and drawings. The Deutsche Forschungsgemeinschaft supported me with a fellowship.

\section{REFERENCES}

1. BRandt, A.: Cloning of double stranded DNA coding for hordein polypeptides. Carlsberg Res. Commun. 44, 255-267 (1979) 
2. Doll, H. \& A. H. D. BrowN: Hordein variation in wild (Hordeum spontaneum) and cultivated (H. vulgare) barley. Can. J. Genet. Cytol. 21, 391-404 (1979)

3. Hirs, C. H. W.: Performic acid oxidation. In: Methods in Enzymology, 11, 197-199 (1967)

4. Holder, S. A. \& J. Ingversen: Peptide mapping of the major components of in vitro synthesized barley hordein: evidence of structural homology. Carlsberg Res. Commun. 43, 177-184 (1978)

5. INGVERSEN, J.: Structure and composition of protein bodies from wild type and high lysine barley endosperm. Hereditas 81, 69-76 (1975)

6. LaEmmLI, U. K.: Cleavage of structural proteins during the assembly of the head of bacteriophage T4. Nature 227, 680-685 (1970)

7. Martin, B., I. Svendesen \& M. Ottesen: Use of carboxypeptidase $\mathrm{Y}$ for carboxyterminal sequence determination in proteins. Carlsberg Res. Commun. 42, 99-102 (1977)

8. Mesrob, B., M. Petrova \& C. P. Ivanov: A comparative study of hordein fractions. Biochim. Biophys. Acta 200, 459-465 (1970)

9. Mifuin, B. J. \& P. R. Shewry: The biology and biochemistry of cereal seed prolamins. In: Seed protein improvement in cereals and grain legumes. International Atomic Energy Agency, pp. 137-158 (1979)
10. Mifun, B. J. \& P. R. Shewry: The synthesis of proteins in normal and high lysine barley seeds. In: Recent Advances in the biochemistry of cereals (Laidman, D. L. \& Wyn Jones, R. G., eds.) London, pp. 239-273 (1979)

11. Oram, R. N., H. Doll \& B. Kole: Genetics of two storage protein variants in barley. Hereditas 80, 53-58 (1975)

12. Poulsen, C.: The cyanogen bromide fragments of the large subunit of ribulosebisphosphate carboxylase from barley. Carlsberg Res. Commun. 44, 163-189 (1979)

13. Shewry, P. R., J. R. S. Ellis, H. M. Pratt \& B. J. Miflin: A comparison of methods for the extraction and separation of hordein fractions from 29 barley varieties. J. Sci. Fd. Agric. 29, 433-44! (1978)

14. Shewry, P. R., H. M. Pratt, R. A. Finch \& B. J. MIFLIN: Genetic analysis of hordein polypeptides from single seeds of barley. Heredity 40 , 463-466 (1978)

15. Soları, R. M. \& E. A. Favret: Polymorphism in endosperm proteins of barley and its genetic control. In: Proc. 2. Int. Barley Genet. Symp. Ed. R. A. Nilan, Washington State Univ. Press pp. 23-31 (1971)

16. Waldschmidi-Leitz, E. \& H. Kling: Zur Darstellung elektrophoretisch einheitlicher Komponenten von Prolaminen. Zeitschr. f. Physiol. Chem. 346, 17-20 (1966) 